\title{
Fauna parasitária de tambaqui Colossoma macropomum (Characidae) cultivado em tanque-rede no estado do Amapá, Amazônia oriental
}

\author{
Evandro Freitas SANTOS ${ }^{1}$, Marcos TAVARES-DIAS ${ }^{1,2}$, Douglas Anadias PINHEIRO ${ }^{1}$, Ligia Rigôr NEVES ${ }^{1}$, \\ Renata das Graças Barbosa MARINHO ${ }^{1}$, Márcia Kelly Reis DIAS ${ }^{1}$
}

\section{RESUMO}

O objetivo principal deste trabalho foi estudar a parasitofauna e a relação hospedeiro- parasito em tambaqui Colossoma macropomum cultivados em tanques-rede no Rio Matapi, município de Santana, estado do Amapá, região da Amazônia oriental, Brasil. Foram examinados 60 tambaquis, dos quais 96,7\% estavam parasitados por protozoários Ichthyophthirius multifiliis (Ciliophora) e Piscinoodinium pillulare (Dinoflagellida), monogenoideas Mymarotheciun boegeri e Anacanthorus spathulatus (Dactylogyridae) e sanguessugas Glossiiphonidae gen. sp. (Hirudinea). Os maiores níveis de parasitismo foram causados por protozoários I. multifiliis e P. pillulare e os menores por sanguessugas Glossiiphonidae gen. sp. Porém, os índices de infestação não tiveram efeitos na saúde dos peixes hospedeiros, uma vez que o fator de condição relativo (Kn) não foi estatisticamente $(\mathrm{p}<0,05)$ correlacionado com a intensidade desses parasitos. Este foi o primeiro relato da ocorrência de I. multifiliis e P. pillulare em C. macropomum cultivados em tanques-rede na Amazônia brasileira.

Palavras-chave: Tanque-rede, Parasitos, Peixe, Prevalência, Sanidade.

\section{Parasitic fauna of tambaqui Colossoma macropomum (Characidae) farmed in cages in the State of Amapá, eastern Amazon}

\begin{abstract}
The purpose of this paper was to evaluate the parasitic fauna and the host-parasite relationship in Colossoma macropomum farmed in cages of Matapi River, municipally of Santana, State of Amapá, in eastern Amazon, Brazil. Of 60 specimens of tambaqui examined, $96.7 \%$ were parasitized by protozoans Ichthyophthirius multifiliis (Ciliophora) and Piscinoodinium pillulare (Dinoflagellida), monogenoideans Mymarotheciun boegeri and Anacanthorus spathulatus (Dactylogyridae), and leeches Glossiphoniidae gen. sp. (Hirudinea). The higher infestation levels were caused by protozoans I. multifiliis and P. pillulare, while the lower infestation levels were caused by leeches. No effects of parasitic infestation rates on fish health were observed. The relative condition factor $(\mathrm{Kn})$ was not correlated with the intensity of parasites found. This was the first record of $I$. multifliis and P. pillulare in C. macropomum farmed in cages in the Brazilian Amazon.
\end{abstract}

KEYwordS: Cage, Parasites, Fish, Prevalence, Sanity.

1 Embrapa Amapá, Laboratório de Aquicultura e Pesca.

2 Rodovia Juscelino Kubitschek, Km 5, 2600, 68903-419, Macapá, AP, Brasil. marcos.tavares@embrapa.br, mtavaresdias@pq.cnpq.br 


\section{INTRODUÇÃO}

O tambaqui Colossoma macropomum é considerado o segundo maior peixe de escama da América do Sul, pois chega a medir $90 \mathrm{~cm}$ de comprimento e a pesar $30 \mathrm{~kg}$ (Gomes et al. 2010; Lopera-Barrero et al. 2011). Como é muito apreciado pelas comunidades ribeirinhas e urbanas da Amazônia, nos últimos anos os estoques naturais deste peixe vêm sofrendo drástica redução (Santos e Santos 2005). O cultivo de tambaqui é então uma das soluçôes para a sobre-exploração dessa espécie em diversos rios da Amazônia. Atualmente, o tambaqui é a espécie nativa mais cultivada na Amazônia brasileira e a mais frequente em pisciculturas de todo o país, pois está presente em 24 dos 27 estados do Brasil. Assim, a produção nacional deste peixe aumentou em $66,0 \%$, no período de 2007 para 2009 (Lopera-Barrero et al. 2011).

No Brasil, a piscicultura de tanque-rede está em franca expansão, pois é considerada uma alternativa de investimento com menor custo e maior rapidez de implantação (Ono e Kubitza 2003). O cultivo de tambaqui em tanques-rede aproveitando recursos hídricos disponíveis tem alcançado boa produtividade, indicando que essa modalidade de piscicultura intensiva é promissora para a criação do tambaqui na região amazônica (Chagas et al. 2007), bem como em outras regiôes brasileiras (Lopera-Barrero et al. 2011). Recentemente, no estado do Amapá, o cultivo de tambaqui em tanques-rede foi introduzido em algumas poucas pisciculturas. Nesse estado, essa modalidade de cultivo é ainda pouca utilizada em virtude das poucas inovações tecnológicas disponíveis e falta de mãode-obra qualificada, além da ausência de políticas públicas direcionadas para este setor produtivo. Além de todos esses fatores, há o manejo inadequado que pode causar graves problemas de doenças nos peixes cultivados nesse sistema intensivo (Tavares-Dias 2011).

A ocorrência de infecçôes parasitárias é fator determinante para o sucesso da piscicultura de qualquer espécie de peixe, principalmente em tanque-rede, sistema intensivo que utiliza elevadas densidades de estocagem dos peixes, visando maior produtividade. Assim, nessa modalidade de piscicultura intensiva, a sanidade é um dos aspectos que náo podem ser jamais negligenciados. Em tambaquis de tanques-rede instalados no Lago Ariauzinho, estado do Amazonas, as infecçôes foram causadas por mixosporídeos Henneguya sp. (60,0\%) e Myxobolus sp. (100\%), monogenoideas Anacanthorus spathulatus e Linguadactyloides brinkmanni (100\%), acantocéfalos Neoechinorhynchus buttnerae (100\%), crustáceos Gamidactylus jaraquensis (60,0\%) e Ergasilus sp. (Varella et al. 2003). Porém, para esse mesmo hospedeiro de tanques-rede do Lago do Paru, estado do Amazonas, o parasitismo foi causado somente por monogenoideas $A$. spathulatus (100\%), Notozothecium janauachensis (85,7\%),
Mymarothecium boegeri (71,4\%), L. brinkmanni (14,3\%) (Morais et al. 2009). Todavia, não há outras informações sobre parasitos em tambaqui de pisciculturas de tanque-rede no Brasil, incluindo o estado do Amapá. Assim, o presente estudo teve como objetivo avaliar a parasitofauna de tambaquis C. macropomum cultivados em tanques-rede instalados no Rio Matapi, município de Santana, estado do Amapá, Brasil.

\section{MATERIAL E MÉTODOS}

\section{Peixes e local de estudo}

Em uma piscicultura de tanque-rede do Rio Matapi $\left(0^{\circ} 03^{\prime} 27,72^{\prime \prime N}\right.$ e $\left.51^{\circ} 14^{\prime} 10,54^{\prime \prime W}\right)$, região do município de Santana, estado do Amapá (Brasil), alevinos de tambaqui Colossoma macropomum foram mantidos durante 60 dias em viveiro escavado de $3.200 \mathrm{~m}^{3}$ e alimentados com ração farelada contendo $45 \%$ de proteína bruta (PB). Posteriormente, quando os peixes atingiram peso médio de $150 \mathrm{~g}$ foram transferidos para tanques-rede de $20 \mathrm{~m}^{3}$, mantidos na densidade de 40 peixes $/ \mathrm{m}^{3}$ e alimentados com ração comercial extrusada contendo $32 \% \mathrm{~PB}$. No final da engorda os peixes foram alimentados com ração extrusada contendo $28 \% \mathrm{~PB}$. Nesta fase, em novembro de 2010,60 peixes $(45,6 \pm 2,7 \mathrm{~cm} \mathrm{e}$ $2.163,5 \pm 324,6 \mathrm{~g}$ ) com aproximadamente um ano de idade, foram coletados de dois tanques-rede e necropsiados para análises parasitológicas.

\section{Coleta, fixação e identificação dos parasitos}

Os peixes foram necropsiados segundo técnicas usuais de coleta, fixação (Eiras et al. 2006) e quantificação dos parasitos (Tavares-Dias et al. 2001 a,b). A identificação dos parasitos foi de acordo com Kritsky et al. (1979), Cohen e Kohn (2005) e Thatcher (2006). Os termos ecológicos adotados foram os recomendados por Rohde et al. (1995) e Bush et al. (1997) .

\section{Parâmetros físico-químicos da água}

No local de instalação dos tanques-rede os parâmetros de qualidade de água foram os seguintes: temperatura de 30,4 \pm $0,05^{\circ} \mathrm{C}$, oxigênio dissolvido $5,2 \pm 0,1 \mathrm{mg} \mathrm{L}^{-1}$, medidos com oxímetro digital (DO-200, YSI Inc, Yellow Springs, Ohio, USA) e o $\mathrm{pH} 4,7 \pm 0,05$, medido com $\mathrm{pHmetro}$ digital ( $\mathrm{pH}$ 100, YSI Inc, Yellow Springs, Ohio, USA).

\section{Fator de condição relativo $(\mathrm{Kn})$ e relação parasito hospedeiro}

De posse dos dados de peso corporal (g) e comprimento total $(\mathrm{cm})$ foi determinado o fator de condição relativo (Le-Cren 1951) dos peixes. O coeficiente de correlação de Spearman (rs) foi usado para determinar possíveis correlaçóes da intensidade de parasitos (parasitos por peixe) com o Kn, comprimento e peso dos hospedeiros (Zar 1999). 


\section{RESULTADOS E DISCUSSÃO}

Dos 60 espécimes de tambaquis que tiveram a boca, olhos, narinas, brânquias e trato gastrointestinal examinados; $96,7 \%$ estavam com as brânquias parasitadas por Ichthyophthirius multifiliis Fouquet, 1876 (Ciliophora) e Piscinoodinium pillulare Schäperclaus, 1954, Lom 1981 (Dinoflagellida), por Mymarothecium boegeri Cohen e Kohn 2005 e Anacanthorus spathulatus Kritsky, Thatcher e Kayton 1979 (Monogenoidea: Dactylogyridae) e por sanguessugas Glossiphoniidae gen. sp (Hirudinea). As maiores taxas de infestação foram por protozoários I. multifiliis e $P$. pillulare, seguido por monogenoideas $M$. boegeri e $A$. spathulatus. Porém, a maior dominância relativa média foi causada por $I$. multifiliis e a menor por sanguessugas (Tabela 1). Não foram encontrados parasitos em outros órgáos examinados.

No Brasil, apesar da expansão da piscicultura, a fauna de parasitos em peixes de piscicultura de tanque-rede tem sido pouco investigada. Entretanto, o surgimento de enfermidades em uma população cultivada é um fenômeno dinâmico, pois a variação na prevalência e o impacto na saúde dos peixes dependem da interação hospedeiro-parasito-ambiente. Assim, é necessário o diagnóstico epidemiológico e acompanhamento constante desses animais nesse tipo de piscicultura que usa elevada densidade de cultivo.

Em espécimes jovens de tambaquis de piscicultura de tanques-rede no Rio Matapi (AP) a prevalência total de parasitos foi de $96,7 \%$. Resultados similares foram descritos para juvenis e jovens de tambaquis (100\%) de tanques-rede mantidos no Lago Ariauzinho (Varella et al. 2003) e para juvenis de tambaquis (100\%) de tanque-rede do Lago Paru (Morais et al. 2009), ambos no estado do Amazonas. Porém, quando comparados a fauna parasitária desses três cultivos distintos, houve diferenças. Nas brânquias de tambaqui do presente estudo, a fauna parasitária foi composta por $I$. multifiliis, P. pillulare, $M$. boegeri, $A$. spathulatus e sanguessugas; enquanto em tambaqui do Lago Ariauzinho a fauna parasitária foi composta por Myxobolus sp., Henneguya sp., A. spathulatus, L. brinkmanni, N. buttnerae, Gamidactylus jaraquensis e Ergasilus sp. (Varella et al. 2003) e em tambaqui do Lago Paru, somente por monogenoideas A. spathulatus, Notozothecium janauachensis, M. boegeri e L. brinkmanni (Morais et al. 2009). Essas diferenças em relaçáo à diversidade parasitária, para um mesmo hospedeiro, se devem ás densidades de cultivo distintas e ao ambiente diferenciado.

A ocorrência de I. multifiliis em peixes de cultivo no Brasil é comum (Eiras et al. 2010; Eiras et al. 2012), mas Amazônia tem sido pouco relatada e não há registro destes parasitos em peixes de tanque-rede. Esse protozoário é o parasito mais comum em peixes de cultivo e responsável por perdas econômicas significativas em pisciculturas de todos os continentes (Tavares-Dias et al. 2001a; Lemos et al. 2007; Pavanelli et al. 2008; Eiras et al., 2010). A prevalência de $I$. multifilis $(96,7 \%)$ nas brânquias de tambaqui de tanques-rede no Rio Matapi (AP) foi similar à descrita para este mesmo hospedeiro (100\%) de viveiros de piscicultura da Venezuela (Fogel et al. 2004). Porém, essa prevalência foi maior do que para tambaquis $(66,6 \%)$ cultivados em viveiros de ManausAM (Tavares-Dias et al. 2006) e da região de Jaboticabal-SP (19,1\%) (Martins e Romero 1996).

Nas brânquias de tambaqui deste estudo, a intensidade de I. multifilis foi maior que a descrita por Fogel et al. (2004) e Tavares-Dias et al. (2006), para o mesmo hospedeiro cultivado em viveiros. Porém, nesses dois estudos, o método usado para a determinação da intensidade desse protozoário oportunista foi distinto. Além disso, a infestação por I. multifilis é de transmissão horizontal (Dickerson 2006; Pavanelli et al. 2008; Eiras et al. 2010) e há uma maior aproximação entre os peixes de tanques-rede quando comparado à piscicultura de viveiros escavados.

O P. pillulare é um protozoário flagelado que tem sido relato parasitando diversas espécies de peixes no Brasil, principalmente em cultivo (Eiras et al. 2010; Eiras et al.

Tabela 1 - Índices parasitológicos nas brânquias de Colossoma macropomum mantidos em tanques-rede no Rio Matapi, estado do Amapá, Amazônia oriental. DP: Desvio padrão

\begin{tabular}{|c|c|c|c|c|}
\hline Parâmetros & Ichthyophthirius multifiliis & Piscinoodinium pillulare & Monogenoidea & Hirudinea \\
\hline Peixes examinados & 60 & 60 & 60 & 60 \\
\hline Peixes parasitados & 58 & 58 & 57 & 44 \\
\hline Prevalência (\%) & 96,7 & 96,7 & 95,0 & 73,3 \\
\hline Intensidade média $\pm \mathrm{DP}$ & $323.759,2 \pm 367215,3$ & $26.173,2 \pm 20780,5$ & $73,2 \pm 86,9$ & $3,4 \pm 2,4$ \\
\hline Variação da intensidade & $155.705-986.888$ & $8.550-93.155$ & $16-659$ & $1-14$ \\
\hline Abundância média & $312.967,2$ & 25300,8 & 69,5 & 2,5 \\
\hline Número total de parasitos & 18.778 .031 & 1.518 .048 & 4.170 & 150 \\
\hline Dominância relativa média & 0,925008 & 0,074779 & 0,000205 & 0,000007 \\
\hline
\end{tabular}


2012). A prevalência $(96,7 \%)$ de $P$. pillulare nas brânquias do tambaqui mantido em tanques-rede no Rio Matapi foi similar a descrita por Fogel et al. (2004), para o mesmo hospedeiro (100\%). Porém, foi maior que a relatada para Piaractus mesopotamicus (24,0\%) e híbridos tambacu (20,0\%) de pesques-pague de Franca-SP (Tavares-Dias et al. 2001a). No presente estudo, a intensidade média de $P$. pillulare (26.173,2/peixe) (Tabela 1) foi menor do que a descrita para P. mesopotamicus (558.959/peixe) e híbridos tambacu (6.658.437/peixe) (Tavares-Dias et al. 2001a). Essas diferenças na prevalência deste protozoário oportunista podem ser atribuídas à diferença de espécies hospedeiras e, além disso, a piscicultura de viveiros escavados muitas vezes apresenta baixa qualidade ambiental, o que favorece a proliferação do protozoário, aumentando a sua intensidade nos peixes. Por outro lado, o $P$. pillulare é um parasito com transmissão horizontal (Noga e Levy 2006; Pavanelli et al. 2008) e nos tanques-rede há uma maior aproximaçáo entre os peixes devido a elevada densidade de estocagem, o que facilitou a transmissão deste parasito entre os tambaquis aqui analisados, causando entáo essa maior prevalência quando comparada aos peixes de viveiros escavados.

Apesar da elevada prevalência de P. pillulare nas brânquias dos peixes deste estudo não houve mortalidade e nem sinais clínicos de enfermidade. Porém, no Sudeste do Brasil, foi registrada mortalidade em $40,0 \%$ dos C. macropomum cultivados em viveiros da região de Jaboticabal (SP), no período de maio a agosto, quando as temperaturas da água variaram de 17 a $24^{\circ} \mathrm{C}$ (Martins et al. 2001). Em temperatura da água adequada $\left(23-25^{\circ} \mathrm{C}\right)$ a reprodução do $P$. pillulare ocorre em 2-3 dias (Noga e Levy 2006; Eiras et al. 2010). Mudanças bruscas de temperaturas ambientais, de $30^{\circ} \mathrm{C}$ para $21{ }^{\circ} \mathrm{C}$, também causam mortalidade em peixes cultivados, pois reduzem a imunidade dos peixes hospedeiros (ShaharomHarrinson et al. 1990; Martins et al. 2001; Noga e Levy 2006), favorecendo a reproduçáo deste parasito e levando a infestaçôes severas.

Nas brânquias de tambaquis de tanques-rede do Rio Matapi (AP) foram coletadas um total de 4.170 espécimes de monogenoideas $M$. boegeri e $A$. spathulatus; enquanto nesse mesmo hospedeiro de tanque-rede do estado do Amazonas foram coletados um total de 7.974 espécimes de $M$. boegeri (17) e 6.894 de A. spathulatus, 256 de N. janauachensis e 17 de L. brinkmanni (Morais et al. 2009). No presente estudo, embora $M$. boegeri e $A$. spathulatus não tenham sido quantificados separadamente, observou-se também maior quantidade de $A$. spathulatus. O A. spathulatus é uma espécie de monogenoidea patogênica, pois pode causar redução na capacidade respiratória do peixe hospedeiro (Kritsky et al. 1979; Morais et al. 2009). Morais et al. (2009) destacaram que em tambaqui de cultivo as infecçôes por $A$. spathulatus devem ter grande atenção, uma vez que são frequentemente encontradas em índices elevados quando comparados a outras espécies de monogenoideas. Porém, Cohen e Kohn (2009) examinando as brânquias de $C$. macropomum cultivados em viveiros escavados de Pentecostes (CE) coletaram um total de 7.372 espécimes de monogenoideas, dos quais 5.266 foram Notozothecium janauachensis, 1.623 M. boegeri e 453 N. euzeti.

Neste estudo, a prevalência de parasitos monogenoideas nas brânquias do tambaqui foi similar a relatada para esse hospedeiro de tanques-rede de duas localidades do estado do Amazonas (Varella et al. 2003; Morais et al. 2009). Porém, a intensidade média, aqui encontrada, foi menor que para tambaquis de tanques-rede no Lago Paru-AM (Morais et al. 2009) e de viveiros escavados do estado do Ceará (Cohen e Kohn 2009), mas foi maior que desse peixe cultivado em tanques-rede do Lago Arialzinho-AM (Varella et al. 2003). Esses resultados distintos devem-se às diferentes densidades e condições ambientais que os peixes estavam submetidos.

Nas brânquias de tambaquis, neste estudo, os níveis de parasitismo por sanguessugas Glossiphoniidae gen. sp. foram similares aos descritos para Hoplosternum littorale do Rio Guandu (Abdallah et al. 2006), mas foram menores que os de Brycon amazonicus cultivados em canais de igarapé no estado do Amazonas (Lemos et al. 2007). Elevado parasitismo por sanguessugas Zeylanicobdella arugamensis causaram grande perda de sangue e inapetência em Epinephelus coioides cultivados, levando esses hospedeiros à morte (CruzLacierda et al. 2000). Em peixes, o parasitismo branquial por sanguessugas pode ser acidental quando em ambientes com presença de aves, répteis e anfíbios, os quais são, geralmente, parasitados temporariamente por esses hirudíneos (Thatcher 2006; Lemos et al. 2007; Eiras et al. 2010), o que parece também ter ocorrido em tambaquis de tanques-rede deste estudo.

Nas brânquias do tambaqui, somente o comprimento mostrou correlaçáo positiva com a intensidade de $P$. pillulare (Figura 1). Porém, não houve correlação entre o fator de condição relativo $(\mathrm{Kn})$ e a intensidade de I. multifiliis, $P$. pillulare, monogenoideas e sanguessugas (Figura 2). Similarmente, em Heterobranchus longfilis selvagem e de cultivo, foi relatada correlação positiva entre o comprimento total e a intensidade de I. multifilis, Chilodonella sp., Trichodina sp. e Hexamita sp. Houve correlaçáo porque os peixes maiores dessa espécie filtradora passam a maior tempo à procura de alimentos, assim ficam mais expostos às infecçóes por esses protozoários (Omeji et al. 2010). Por outro lado, em alevinos de Oncorhynchus mykiss a intensidade de I. multifilis não foi correlacionada com o comprimento total (Ogut et al. 2005). Portanto, o tamanho dos peixes hospedeiros, um reflexo de sua idade, pode ser um importante fator na variação da intensidade das infracomunidades parasitárias. 


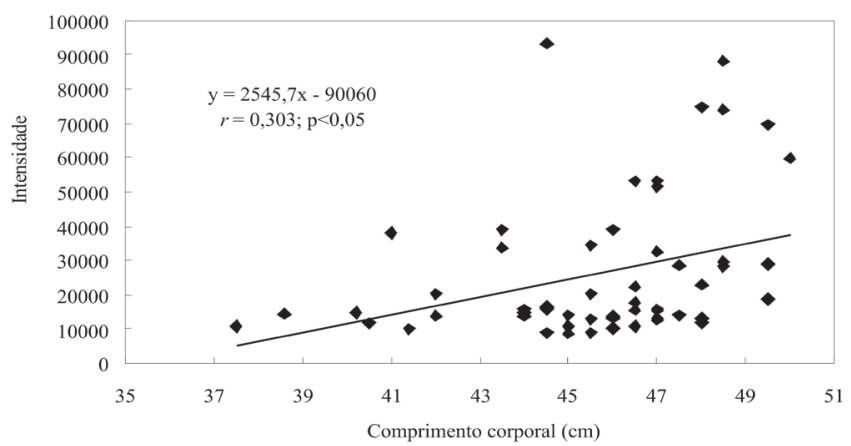

Figura 1- Correlação entre a intensidade (número de parasitos/peixe) de Piscinoodinium pillulare e o comprimento de Colossoma macropomum (N=58) mantido em tanquesrede no Rio Matapi, estado do Amapá, Amazônia oriental.
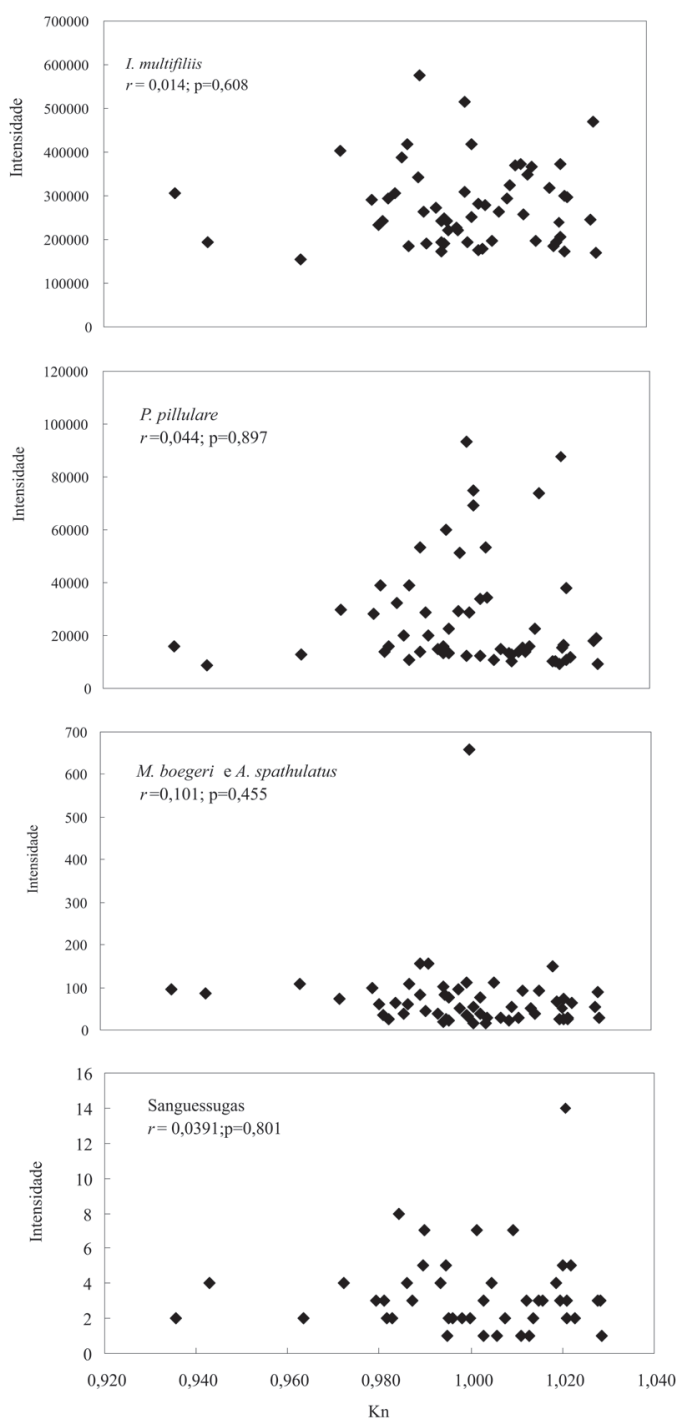

Figura 2 - Correlação do fator de condição relativo $(\mathrm{Kn})$ com a intensidade intensidade (número de parasitos/peixe) de Ichthyophthirius multifiliis, Piscinoodinium pillulare, Mymarothecium boegeri e Anacanthorus spathulatus e sanguessugas Glossiphoniidae gen.sp nas brânquias de Colossoma macropomum $(\mathrm{N}=58)$ mantidos em tanques-rede no Rio Matapi, estado do Amapá, Amazônia oriental.
Em tambaquis de tanques-rede instalados no Rio Matapi (AP), o moderado parasitismo por I. multifiliis, P. pillulare, monogenoideas e sanguessugas não afetou a saúde dos hospedeiros, pois o Kn não foi estatisticamente correlacionado com a intensidade desses parasitos. Similarmente, não foi demonstrada correlaçáo significativa entre o fator de condição e a baixa intensidade de I. multifilis e sanguessugas Placobdella sp. em B. amazonicus cultivados em canais de igarapé (Lemos et al. 2007). Porém, foi relatada correlação negativa entre a elevada abundância de Urocleidoides paradoxus e Gamispatulus schizodontis e o Kn em Leporinus lacusttis e Leporinus elongatus de ambiente natural (Guidelli et al. 2011). Portanto, o fator de condiçâo é um indicador quantitativo do grau de bemestar dos peixes que pode ser usado para avaliar os efeitos do parasitismo na saúde dos hospedeiros (Lemos et al. 2007; Guidelli et al. 2011).

\section{CONCLUSÕES}

Em tambaqui, a presença de uma diversidade relativamente pequena de parasitos e em níveis moderados de infestação devem-se à idade dos hospedeiros (cerca de um ano de idade), além da baixa densidade de estocagem dos peixes em boas condiçôes ambientais no Rio Matapi. Esses resultados foram os primeiros dados sobre índices epidemiológicos de tambaquis criados em tanques-rede na Amazônia oriental. Porém, para esse peixe, estudos adicionais deverão ser conduzidos durante todas as fases do cultivo e nas diferentes densidades de estocagem usualmente praticadas em pisciculturas de tanque-rede.

\section{AGRADECIMENTOS}

Ao Conselho Nacional de Pesquisa e Desenvolvimento Tecnológico (CNPq), pelo apoio financeiro (Proc: 578159/2008-2) e pela bolsa de Produtividade em Pesquisa a M. Tavares-Dias (Proc: 300472/2008-0). 


\section{BIBLIOGRAFIA CITADA}

Abdallah, V.D.; Azevedo, R.K.; Luque, J.L. 2006. Ecologia da comunidade de metazoários parasitos do tamboatá Hoplosternum littorale (Hancock 1828) (Siluriformes: Callichthyidae) do rio Guandu, estado do Rio de Janeiro, Brasil. Acta Scientiarum Biological Sciences, 28: 413-419.

Bush, A.O.; Lafferty, K.D.; Lotz, J.M.; Shostak, W. 1997. Parasitology meets ecology on its own terms: Margolis et al. Journal of Parasitology, 83: 575-583.

Chagas, E.C.; Gomes, L.C.; Júnior, H.M; Roubach, R. 2007. Produtividade de tambaqui em tanque-rede com diferentes taxas de alimentação. Ciência Rural, 37: 1109-1115.

Cohen, S.C.; Kohn, A. 2005. A new species of Mymarothecium and new host and geographical records for M. viatorum (Monogenea: Dactylogyridae), parasites of freshwater fishes in Brazil. Folia Parasitologica, 52: 307-310.

Cohen, S.C.; Kohn, A. 2009. On Dactylogyridae (Monogenea) of four species of characid fishes from Brazil. Check List, 5: 351-356.

Cruz-Lacierda, E.R.; Toledo, D.J.; Tan-Fermin J. D; Burreson E. M. 2000. Marine leech (Zeylanicobdella arugamensis) infestation in cultured orangespotted grouper, Epinephelus coioides. Aquaculture, 185:191-196.

Dickerson, H.W. 2006. Ichthyophthirius multifiliis and Cryptocaryon irritans (Phylum Ciliophora), p.116-153. In: Woo, P.T.K. (Ed.). Fish diseases and disorders: protozoan and metazoan infections. $2^{\text {th }}$ ed. Biddles, King's Lyn: UK.

Eiras, J.C.; Takemoto, R.M.; Pavanelli, G.C. 2006. Métodos de estudo e técnicas laboratoriais em parasitologia de peixes. $2^{\mathrm{a}} \mathrm{Ed}$. Eduem,Maringá. 199 pp.

Eiras, J.C.; Takemoto, R.M.; Pavanelli, G.C. 2010. Diversidade dos parasitos de peixes de água doce do Brasil. Clichetec, Maringá. $333 \mathrm{pp}$.

Eiras, J.C.; Takemoto, R.M.; Pavanelli, G.C.; Luque, J.L. 2012. Checklist of protozoan parasites of fishes from Brazil. Zootaxa, 3221: 1-25.

Fogel, D.E.D.; Zambrano, J.L.F.; Gonzalez, I. 2004. Parasitosis en Colossoma macropomum (Pisces: Characidae) cultivado, ocasionada por los protozoos Ichthyophthirius multiflis (Fouquet) y Piscinoodinium pillulare (Schaperclaus). Saber, Universidad de Oriente, 16: 3-8.

Gomes, L.C.; Simões, L.N.; Araújo-Lima, C.A.R.M. 2010. Tambaqui (Colossoma macropomum), p.175-204. In: Baldisserotto, B.; Gomes, L.C. (Org.). Espécies nativas para piscicultura no Brasil. 2a. Ed. Editora UFSM, Santa Maria.

Guidelli, G; Tavechio, W.L.G.; Takemoto, R.M; Pavanelli, G.C. 2011. Relative condition factor and parasitism in anostomid fishes from the floodplain of the Upper Paraná River, Brazil. Veterinary Parasitology, 177: 145-151.

Kritsky, D.C.; Thatcher, V.E.; Kayton, R.J. 1979. Neotropical Monogenoidea. The Anacanthorinae Price, 1967, with the proposal of four new species Anacanthorus Mizelle e Price, 1965 from Amazonian fishes. Acta Amazonica, 9:355-361.
Le-Cren, E.D. 1951. The length-weight relationship and seasonal cycle in gonadal weight and condition in the perch (Perca fluviatilis). Journal of Animal Ecology, 20: 201-219.

Lemos, J.G; Tavares-Dias, M.; Sales, R.S.A., Nobre-Filho, G.R.; Fim, J.D.I. 2007. Parasitos nas brânquias de Brycon amazonicus (Characidae, Bryconinae) cultivados em canais de igarapé do Turumã-Mirim, estado do Amazonas, Brasil. Acta Scientiarum Biological Sciences, 29: 217-222.

Lopera-Barrero, N.M.; Ribeiro, R.P.; Povh, J.A.; Vargas, L.D.M.; Poveda-Parra, A.R.; Digmayer, M. 2011. As principais espécies produzidas no Brasil, 143-215. In: Lopera-Barrero, N.M.; Ribeiro, R.P.; Povh, J.A.; Vargas, L.D.M.; Poveda-Parra, A.R.; Digmayer, M. Produção de organismos aquáticos: uma visão geral no Brasil e no mundo. Agrolivros, Guaíba.

Martins, M.L; Romero, N.G. 1996. Efectos del parasitismo sobre el tejido branquial en peces cultivados: Estúdio parasitológico e histopatologico. Revista Brasileira de Zoologia, 13: 489-500.

Martins, M.L.; Moraes, J.R.E.; Andrade, P.M.; Schalch, S.H.C. ; Moraes, F.R., 2001. Piscinoodinium pillulare (Schäperclaus 1954) Lom, 1981 (Dinoflagellida) infection in cultivated freshwater fish from Northeast region of São Paulo State, Brazil. Parasitological and pathological aspects. Brazilian Journal of Biology, 61: 639-644.

Morais, A.M.; Varella, A.M.B; Correa, M.A.V.; Malta, J.C.O. 2009. A fauna de parasitos em juvenis de tambaqui Colossoma macropomum (Cuvier, 1818) (Characidae: Serrasalminae) criados em tanques-rede em lago de várzea da Amazônia central. Biologia Geral Experimental, 9: 14-23.

Noga, E.J.; Levy, M.G. 2006. Phylum Dinoflagellata, p.16-45. In: Woo, P.T.K. (Ed.). Fish diseases and disorders: protozoan and metazoan infections. $2^{\text {th }}$ ed. Biddles, King's Lyn: UK.

Ogut, H.; AkyoL, A.; Alkan, M.Z. 2005. Seasonality of Ichthyophthirius multifliis in trout (Oncorhynchus mykiss) farms of the eastern Black Sea region of Turkey. Turkish Journal of Fisheries and Aquatic Sciences, 5: 23-27.

Omeji, S.; Solomon, S.G.; Obande, R.A. 2010. A Comparative study of the common protozoan parasites of Heterobranchus longifilis from the wild and cultured environments in Benue State. Pakistan Journal of Nutrition, 9: 865-872.

Ono, E.A.; Kubitza, F. 2003. Cultivo de peixes em tanques-rede. $3^{\text {a }}$.Ed. Ono, E.A. (ed.): Jundiaí. 112 pp.

Pavanelli, G.C.; Eiras, J.C.; Takemoto, R.M. 2008. Doença de peixes, profilaxia, diagnóstico e tratamento. Eduem, Maringá. 311 pp.

Rohde, K.; Hayward, C.; Heap, M. 1995. Aspects of the ecology of metazoan ectoparasites of marine fishes. International Journal for Parasitology, 25: 945-970.

Santos, G.M.; Santos, A.C.M. 2005. Sustentabilidade da pesca na Amazônia. Estudos Avançados, 19: 165-182.

Shaharom-Harrison, F.M.; Anderson, I.G.; Siti, A.Z.; Noor, A.M; Shazili, K.J.; Azmi, T.I. 1990. Epizootics of Malaysian cultured freshwater pond fishes by Piscinoodinium pillulare (Schaperclaus 1954) Lom 1981. Aquaculture, 86: 127-138. 
Tavares-Dias, M. 2011. Piscicultura continental no estado do Amapá: diagnóstico e perspectivas. Boletim de Pesquisa e Desenvolvimento, Embrapa Amapá, 81:1-38.

Tavares-Dias, M.; Martins, M.L.; Moraes, F.R. 2001a. Fauna parasitária de peixes oriundos de pesque-pague do município de Franca, São Paulo, Brasil. I. Protozoários. Revista Brasileira de Zoologia, 18: 67-79.

Tavares-Dias, M.; Moraes, F.R.; Martins, M.L.; Kronka, S.N. 2001 b. Fauna parasitária de peixes oriundos de pesque-pagues do município de Franca, São Paulo, Brasil. II. Metazoários. Revista Brasileira de Zoologia, 18: 81-95.

Tavares-dias, M.; Lemos, J.R.G.; Andrade, S.M.S.; Pereira, S.L.A. 2006. Ocorrência de ectoparasitos em Colossoma macropomum Cuvier, 1818 (Characidae) cultivados em estação de piscicultura na Amazônia Central. CIVA. p.726-731 (http:// www. revistaaquatic.com/civa2006/coms/completo.asp?cod=150). Acesso em 16/ 09/2011.

Thatcher, V.E. 2006. Amazon fish parasites. 2a ed. Pensoft Publishe, Sofia, Moscow. 508 pp.

Varella, A.M.B; Peiro, S.N; Malta, J.C.O. 2003. Monitoramento da parasitofauna de Colossoma macropomum, cultivado em tanques-rede em um lago de várzea na Amazônia, Brasil. XII Simpósio Brasileiro de Aquicultura, Goiânia, 2: 95-106.

Zar, J.H.1999. Biostatistical analysis. 5a ed. Prentice-Hall, New Jersey. 663 pp.

Recebido em: 21-09-2011

Aceito em: 13-03-2012 
